\title{
PRODUCCION DE NARINGENINA POR Aspergillus niger IB-56
}

\section{(Production of naringenin by Aspergillus niger IB-56)}

\author{
Cristina Rubio $\mathbf{M}^{1^{*}}$; Teresa Alurralde ${ }^{1}$; \\ Soledad Suárez ${ }^{1}$ \& Antonio Navarro I $^{1}$ \\ ${ }^{1}$ Cátedra Biotecnología Microbiana, Instituto de Biotecnología. \\ Licenciatura en Biotecnología. Facultad de Bioquímica, \\ Química y Farmacia. \\ Universidad nacional de Tucumán. \\ Ayacucho 467. (4000). \\ Tucumán. Argentina. \\ Autor para Correspondencia: Email1m1rubio25@hotmail.com
}

Palabras claves: Aspergillus niger, flavonoides, naringenina, producción Key words: Aspergillus niger, flavonoid, naringenin, production

\section{RESUMEN}

Aspergillus niger IB-56 fue usado como biocatalizador para la transformación de naringina en naringenina, un flavonoide de gran importancia en la industria farmacéutica. En el proceso biotecnológico planteado, se obtuvo un rendimiento $(\mathrm{Yp} / \mathrm{s}=0,4 \mathrm{~g} / \mathrm{g})$, productividad $(P v=0,1 \mathrm{~g} / \mathrm{Lh})$ y eficiencia del $85 \%$ similar al valor encontrado con naringinasa parcialmente purificada $(\mathrm{Yp} / \mathrm{s}=0,45 \mathrm{~g} / \mathrm{g} ; \quad P v=0,12 \mathrm{~g} / \mathrm{Lh}$ y $E f=92 \%)$. Los costos del proceso son bajos comparados a los ocasionados por la extracción, concentración y purificación de la enzima.

\footnotetext{
ABSTRACT

Aspergillus niger IB-56 was used like biocatalizador for the transformation of naringin in naringenin, a flavonoid of great important in the pharmaceutical industry. In the raised biotechnological process, one obtained a yield ( $\mathrm{Yp} / \mathrm{s}=0.4 \mathrm{~g} / \mathrm{g})$, productivity $(P v=0.1 \mathrm{~g} / \mathrm{Lh})$ and efficiency of $85 \%$ similar to the value found with naringinase partially purified $(Y p / s=0.45 \mathrm{~g} /$ $g ; P v=0.12 \mathrm{~g} / \mathrm{Lh}$ and $E f=92 \%$ ).

The costs of the process low are compared to the caused ones by the extraction, concentration and purification on the enzyme.
}

\section{INTRODUCCION}

Naringenina $\left(4^{\prime}, 5^{\prime}, 7^{\prime}\right.$ - trihidroxi-flavonona), es un flavonoide que se encuentra en el grupo de las flavanonas junto a naringina y hesperidina. Estos flavonoides tienen importancia para la industria farmacéutica porque presentan propiedades antioxidantes, antitrombóticas y antiinflamatorias (González Gallego, 2007).

De acuerdo a Borradaile et al. (2003) y Nahmias et al. (2008), naringenina tiene gran aplicación en medicina, porque puede bloquear al virus de la hepatitis $\mathrm{C}(\mathrm{HCV})$, impidiendo la infección de las células sanas. Disminuye los lípidos del plasma, inhibe la secreción de la apolipoproteína B (apo B) de las células del hematoma humano y produce la esterificación del colesterol. Debido a que el organismo humano no puede sintetizar estas sustancias químicas protectoras, las mismas se deben suplementar en la alimentación.

Naringenina se obtiene por hidrólisis de naringina (4',5',7'trihidroxi-flavonona 7-ramnoglucósido), éste se encuentra mayormente en el mesocarpio de los frutos cítricos y es uno de los responsables del sabor amargo de los jugos después de su extracción (Yusof et al., 1990).

La hidrólisis de naringina se puede realizar por procesos químicos o enzimáticos. Estos últimos presentan las siguientes ventajas: son específicos, mantienen las características organolépticas del alimento y no generan compuestos secundarios. El mayor inconveniente de este proceso es el elevado costo, debido a los numerosos pasos 
de purificación necesarios para la obtención de la enzima (Johnson \& Chandler, 1988; Puri \& Banerjee, 2000).

La enzima naringinasa, llamada así comercialmente porque su acción más conocida es la hidrólisis de naringina, es un complejo enzimático que contiene las siguientes actividades extracelulares, $\alpha$-L-ramnosidasa (EC 3.2.1.40) y Flavonoide $\beta$-D-glucosidasa (EC 3.2.1.21). En la Figura 1 se muestra que en un primer paso, la enzima $\alpha$-L-ramnosidasa hidroliza el enlace ramnosa de la naringina, originando, prunina(4'5,7'trihidroxiflavonona-7-glucósido). Posteriormente, la enzima Flavonoide $\beta$-D-glucosidasa libera la unión de la glucosa del flavonoide dejando como producto final naringenina ( ${ }^{2}$ ekeroçlu et al., 2006; Vila Real et al., 2006).

En un principio, naringinasa fue extraída a partir de vegetales como apio, hojas de uvas, de plantas como Fagopyrum esculentum (trigo sarraceno), de Corticium rolfsii (hongo patógeno de plantas) y del hígado del gastrópodo marino Turbo cornutus, pero debido a la baja concentración de la enzima, los procesos de extracción presentaban elevados costos (Kurosawa et al., 1973; Bourbouze et al., 1976). Debido a esto, por razones técnicas y económicas las enzimas de origen microbiano encuentran un papel importante para el futuro, principalmente las provenientes de hongos filamentosos. Estos son heterótrofos, nutricionalmente poco exigentes y grandes productores de enzimas extracelulares que les permiten desarrollar sobre variados compuestos naturales como celulosa, quitina, lignina, cáscara de cítricos, entre otros (Gallego et al., 2001; Soria \& Ellenrieder, 2002; Puri \& Karla, 2005; Puri et al., 2005; Hui et al., 2011). En este trabajo se evaluó el uso de un microorganismo capaz de sintetizar naringinasa para producir naringenina, a fin de disminuir los costos del proceso y evitar las etapas de extracción y purificación de la enzima.

El objetivo del trabajo fue utilizar Aspergillus niger $I B-56$, para la bioconversión de naringina a narigenina y comparar los parámetros de producción respecto a la enzima naringinasa parcialmente purificada.

\section{MATERIALES Y METODOS}

Microorganismo: Se usó una cepa de Aspergillus niger $I B-56$ obtenida del cepario del Instituto de Biotecnología. Ésta se mantuvo por repiques sucesivos en medio de Czapeck, la misma se incubó a $30^{\circ} \mathrm{C}$ durante $96 \mathrm{~h}$ y se conservó a $4{ }^{\circ} \mathrm{C}$.

Cultivo de $A$. niger IB-56 de 24 h: Se preparó una solución de conidios que contiene $2 \times 10^{6}$ conidios $/ \mathrm{ml}$, que corresponde a una absorbancia de 0,25 para una longitud de onda de $540 \mathrm{~nm}$. De esta solución se extrajo $5 \mathrm{ml}$ y se agregó a $50 \mathrm{ml}$ de medio de producción de la siguiente composición, en $(\mathrm{g} / \mathrm{L}): 1,0, \mathrm{~K}_{2} \mathrm{HPO}_{4} ; 3,0, \mathrm{NaNO}_{3} ; 0,5 \mathrm{KCl}$ y $0,5, \mathrm{MgSO}_{4} \times 7 \mathrm{H}_{2} \mathrm{O}$ y como fuente de carbono $10 \mathrm{~g}$ de pulpa de limón ( $92 \%$ humedad y $1 \%$ de flavonoides). El medio se llevó a pH 5,0 con $\mathrm{NaOH}(20 \%$, v/v) y se esterilizó a 1 at. 10 min. Los cultivos se incubaron a $30{ }^{\circ} \mathrm{C}$ y $250 \mathrm{rpm}$ en un agitador rotatorio con control de temperatura durante $24 \mathrm{~h}$. Posteriormente, el micelio se separó por filtración del medio de cultivo fermentado, se lavó varias veces con agua destilada estéril y se colocó en tampón ácido acético-acetato de sodio $(0,1 \mathrm{M}, \mathrm{pH} 5,0)$ hasta su utilización para la producción del flavonoide (naringenina).

Producción y parcial purificación de naringinasa: Para la producción de la enzima, se tomó $5 \mathrm{ml}$ de la solución de conidios de $A$. nigerIB-56 ( $2 \times 10^{6}$ conidios $\left./ \mathrm{ml}\right)$ y se agregó a $50 \mathrm{ml}$ de medio de producción (pH 5,0). Los cultivos se incubaron a $30^{\circ} \mathrm{C}, 250 \mathrm{rpm}$, durante $72 \mathrm{~h}$ de incubación. Posteriormente, el micelio se separó por filtración, el filtrado obtenido se usó como fuente de naringinasa extracelular y se guardó a $4{ }^{\circ} \mathrm{C}$ hasta su concentración y parcial purificación con la sal de amonio.

Este filtrado se precipitó con $\left(\mathrm{NH}_{4}\right)_{2} \mathrm{SO}_{4}$ al $50 \%$ de saturación y se centrifugó a $10.000 \mathrm{rpm}$ durante $10 \mathrm{~min}$. El precipitado se resuspendió en tampón acetato de sodio-ácido acético $(0,1 \mathrm{M}-\mathrm{pH} 4,2)$ y se colocó en membrana de diálisis. Se dializó toda la noche en el mismo tampón acetato, y posteriormente se concentró el dializado cubriendo la membrana de diálisis con $15 \mathrm{~g}$ de carboximetilcelulosa (Sigma) durante $6 \mathrm{~h}$. El

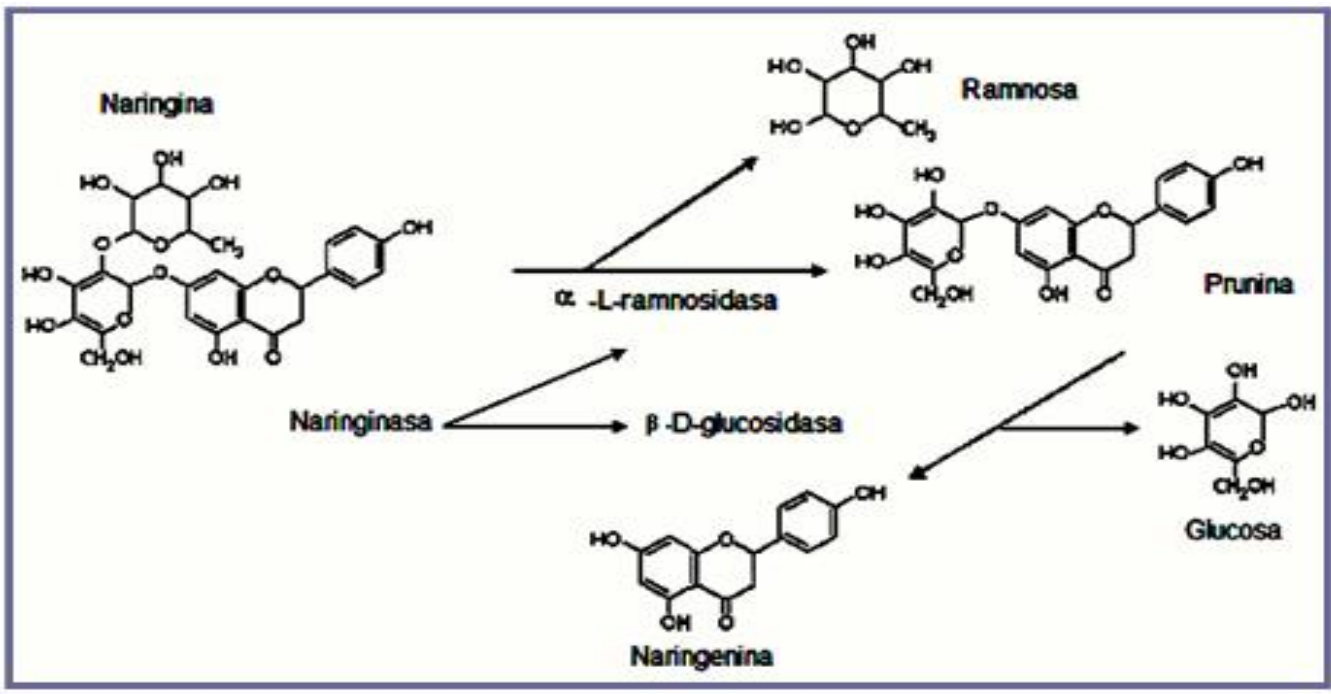

Figura 1:

Mecanismo de acción del complejo enzimático naringinasa sobre naringina en el proceso de conversión a naringenina. 
extracto enzimático parcialmente purificado se mantuvo a 4 ${ }^{\circ} \mathrm{C}$ hasta su utilización y determinación de actividad enzimática.

Producción de naringenina por $A$. niger IB-56: A $100 \mathrm{ml}$ medio de producción ( $\mathrm{pH} 5,0)$ que contiene naringina ( $5 \mathrm{~g} / \mathrm{L})$ como sustrato, se agregó $5 \mathrm{ml}$ del cultivo de $\boldsymbol{A}$. niger IB56 de $24 \mathrm{~h}(0,9 \mathrm{~g} / \mathrm{L}$ en peso seco). La producción se llevó a cabo en un reactor de $250 \mathrm{ml}$, a $30^{\circ} \mathrm{C}$ y $250 \mathrm{rpm}$. Se tomaron muestras cada $3 \mathrm{~h}$ durante $24 \mathrm{~h}$ de incubación.

Producción de naringenina por naringinasa parcialmente purificada: A $100 \mathrm{ml}$ de tampón acido acéticoacetato de sodio $(0,1 \mathrm{M} ; \mathrm{pH} 4,2)$ se agregó naringina $(5 \mathrm{~g} / \mathrm{L})$ y $1 \mathrm{ml}$ del extracto concentrado de naringinasa $(4,2 \mathrm{U} / \mathrm{ml})$. $\mathrm{La}$ producción se llevó a cabo en un reactor de $250 \mathrm{ml}$, a $37^{\circ} \mathrm{C} \mathrm{y}$ $250 \mathrm{rpm}$. Se tomaron muestras cada $3 \mathrm{~h}$ durante $24 \mathrm{~h}$ de incubación.

\section{Determinaciones}

Biomasa: El micelio de Aspergillus nigerIB-56 se separó del caldo de filtración, se lavó varias veces con agua destilada y se secó en estufa a $105^{\circ} \mathrm{C}$ hasta peso constante.

Actividad Enzimática: Para la determinación de actividad, la mezcla de reacción se preparó con $0,10 \mathrm{ml}$ de extracto enzimático (enzima extracelular), 0,25 $\mathrm{ml}$ de una solución de naringina al $0,1 \%(\mathrm{w} / \mathrm{v})$ y $0,15 \mathrm{ml}$ de tampón ácido acético-acetato de sodio $(0,1 \mathrm{M}) \mathrm{pH} 4,2$. La mezcla se incubó a $37{ }^{\circ} \mathrm{C}$ durante $20 \mathrm{~min}$, los azúcares reductores liberados por acción enzimática se determinaron por el método de Somogyi (1945). Una Unidad naringinasa, se define como la cantidad de enzima que cataliza la liberación de $1 \mu$ mol de azúcares reductores por min, a pH 4,2 y a $37^{\circ} \mathrm{C}$.

Flavonoides: Los flavonoides totales fueron determinados por el método de Davis (1947). Naringina, y naringenina por absorción a 375 y $310 \mathrm{~nm}$, respectivamente, de acuerdo a Habelt \& Pittner (1983).

Variables del proceso fermentativo: Coeficiente de rendimento de producto respecto al sustrato, $\mathrm{Y}_{\mathrm{p} / \mathrm{s}}=\mathrm{g} / \mathrm{g}$ (donde $\mathrm{P} / \mathrm{S}$, corresponde a concentración de producto (naringenina) / concentración inicial de naringina). Coeficiente de rendimiento de producto respecto a la biomasa, $\mathrm{Y}_{\mathrm{p} / \mathrm{x}}=\mathrm{g} / \mathrm{g}$ (donde $\mathrm{P} / \mathrm{X}$, es concentración de naringenina / concentración de biomasa). Productividad volumétrica: $\mathrm{Pv}$ $=\mathrm{g} / \mathrm{Lh}$, se calcula como gramos de naringenina producida (g) / litro de medio (L) y por hora (h). Eficiencia (Ef) se calcula por la siguiente ecuación:

$$
E=\frac{R p}{R t} \times 100=\%
$$

donde $\mathrm{Rp}$, rendimiento práctico, es la concentración de naringenina obtenido en el proceso y Rt, rendimiento teórico, es la concentración de naringenina que se tendría que obtener a partir de la concentración inicial de naringina (Doran, 1998).

Reproducibilidad de los resultados: Todos los ensayos se realizaron 3 veces por duplicado y los valores reportados son el promedio de 6 valores independientes. Los datos fueron analizados estadísticamente para obtener la desviación estándar con un MS-Excel. Los valores promedio fueron comparados, usando ANOVA, a $\mathrm{P}<0,5 \mathrm{y}$ en un F-test.

\section{RESULTADOS Y DISCUSION}

\section{Producción de naringenina}

La cepa de Aspergillus niger IB-56 se cultivó previamente durante $24 \mathrm{~h}$ en el medio con pulpa de limón, para inducir la síntesis de naringinasa y obtener un microorganismo con enzimas activas y en fase de crecimiento exponencial.

Para la producción de naringenina, los experimentos se llevaron a cabo en proceso discontinuo y por un sistema de cultivo sumergido y agitado. En estos cultivos, Aspergillus niger IB-56 desarrolló como un agregado de hifas entrecruzadas en formas de ovillo (Figura 2). Esto se debe a que la agitación genera fuerzas de cizalla que producen movimiento y deformación del líquido; a su vez provocan la fragmentación de las hifas resultando de ello un micelio más corto pero más ramificado que puede presentarse como pellets (ovillo). Por el contrario, de acuerdo a Wainwright (1992) otros hongos, como Neurospora sp. y Penicillium sp., cuando desarrollan en cultivos sumergidos forman un micelio corto y disperso en el interior del líquido. Esto se debe a que en medios líquidos, el medio ambiente es homogéneo y los nutrientes se hallan más fácilmente disponibles que en medios sólidos (Martín \& Demain, 1978). Mientras que sobre superficies sólidas (agar, madera, cáscara cítrica, etc.) los hongos desarrollan un micelio extendido, llegando a observarse hifas muy largas, a fin de encontrar los nutrientes necesarios para el crecimiento celular.

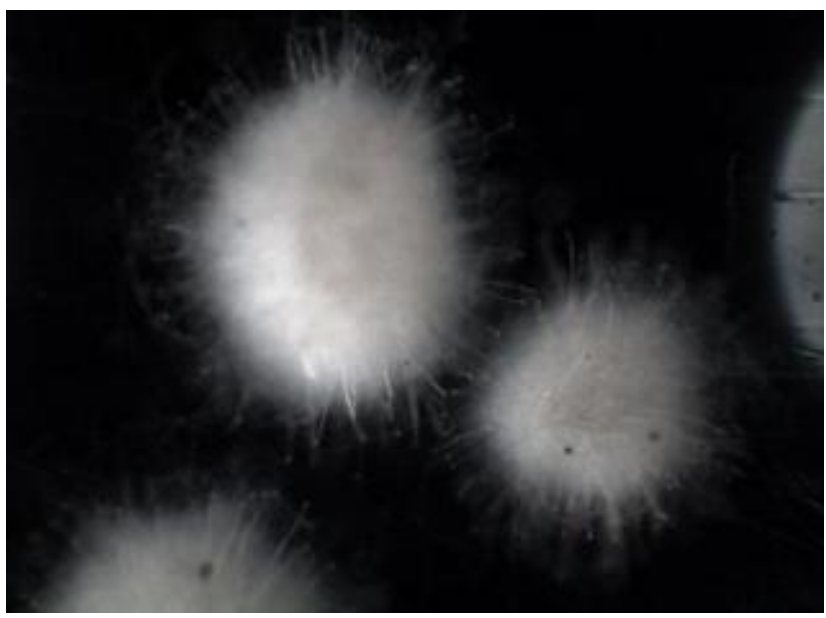

Figura 2: Desarrollo característico del cultivo de Aspergillus niger IB-56 en medios líquidos agitados. Se observa el entrecruzado de las hifas formando los típicos pellets. 
En la Figura 3 se muestra la cinética de producción de naringenina por $A$. niger IB-56. La máxima producción del flavonoide se obtiene a las $24 \mathrm{~h}$ de incubación, este aumento coincide con la disminución de la concentración de naringina y de los azúcares reductores en el medio. Como se muestra en la figura 3, las enzimas del hongo hidrolizaron los azúcares del flavonoide (ramnosa y glucosa) para ser usados como fuente de carbono para el desarrollo y mantenimiento celular.

Cuando se utilizó naringinasa parcialmente purificada, la máxima producción de naringenina $(2,23 \mathrm{~g} / \mathrm{L})$ se obtuvo a las $15 \mathrm{~h}$ de incubación. Paralelamente se determinó un aumento del contenido de azúcares reductores en el medio, liberados por acción enzimática. Esta acumulación de ramnosa y glucosa en el medio puede tener un efecto negativo sobre la actividad enzimática y puede ser limitante cuando se trabaja con altas concentraciones de sustrato. Por el contrario, cuando se utilizó el hongo este no sucede ya que los azúcares fueron asimilados por el microorganismo.

En la tabla 1 se muestran los parámetros fermentativos obtenidos en la producción de naringenina por el hongo y con la enzima parcialmente purificada.

Los valores del coeficiente de rendimiento de producto, Yp/s y la productividad (Pv) obtenidos con $A$. nigerIB-56 son similares a aquellos conseguidos con la enzima parcialmente purificada (Tabla 1). Si consideramos la producción de naringenina por hora $(\mathrm{g} / \mathrm{h})$, el hongo $I B-56$ produjo $0,1 \mathrm{~g} / \mathrm{h}$ del metabolito similar al obtenido con la enzima parcialmente purificada $(0,14 \mathrm{~g} / \mathrm{h})$.

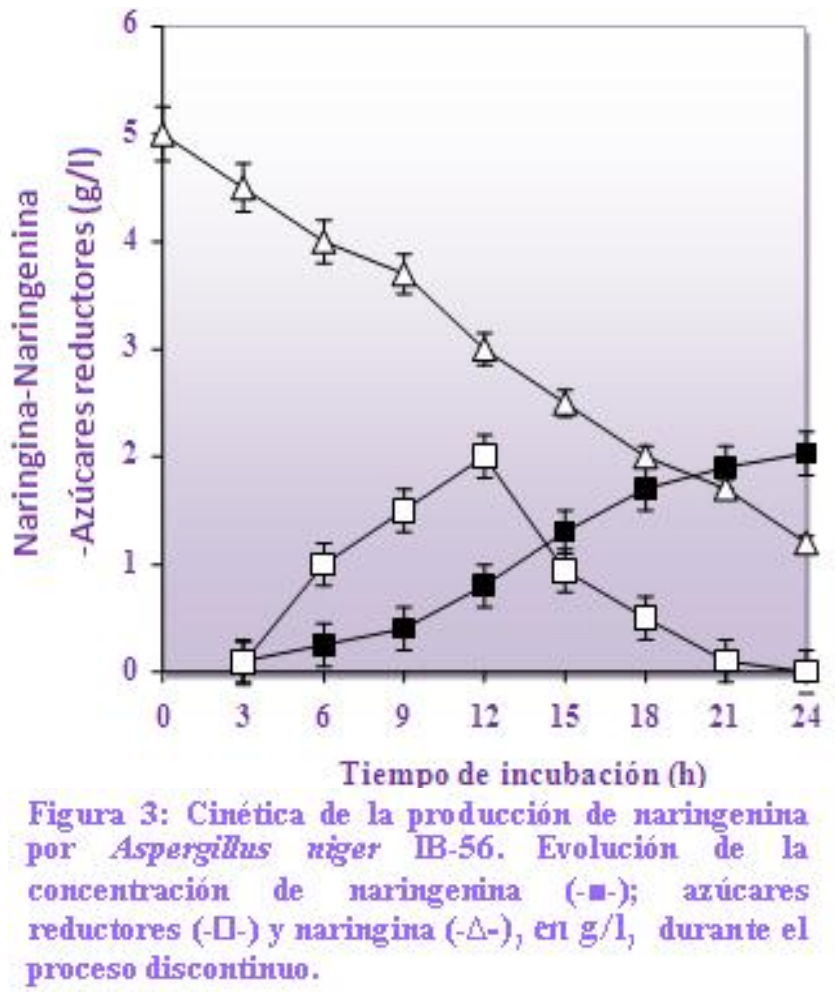

La Eficiencia (Ef), un parámetro importante del proceso fermentativo, mostró que cuando se utilizó $\boldsymbol{A}$. nigerIB-56, como biocatalizador, se obtuvo un $85 \%$ de eficiencia en la producción de naringenina, respecto al valor encontrado con naringinasa parcialmente purificada $(\mathrm{Ef}=94$ $\%)$. Resultados similares $(\mathrm{Ef}=82 \%)$ fueron encontrados con naringinasa de Penicillium sp., inmovilizada por unión covalente a virutas de madera (Puri et al., 2005) y una Ef= $70 \%$, a $60^{\circ} \mathrm{C}$, cuando naringinasa fue inmovilizada en esferas de geles de alginato de calcio (Puri et al., 1996). En estos casos el proceso es altamente costoso debido al proceso de purificación e inmovilización de la enzima, si bien, las reacciones a temperaturas altas $\left(60^{\circ} \mathrm{C}\right)$ minimizan las contaminaciones por bacterias, el gasto energético por calefacción incrementa el costo final del proceso enzimático.

En conclusión, de acuerdo a los resultados presentados, el proceso biotecnológico propuesto tiene ventajas porque se utilizó un hongo como Aspergillus niger $I B-56$, con el cual se logró una Eficiencia del $85 \%$ en la producción de naringenina, un $9,5 \%$ menor que aquella obtenida con la enzima parcialmente purificada. Por otra parte, emplear el microorganismo permite retener la integridad estructural de la enzima; aumentar la síntesis de naringinasa e incrementar la concentración de naringenina deseada al reciclar el medio de fermentación en el reactor, sin que se inactive el biocatalizador.

El proceso biotecnológico planteado podría extrapolarse a procesos donde se empleen materias primas económicas como residuos cítricos, cáscaras de manzanas, residuos de la soja, etc., que contengan flavonoides para disminuir, aún más, los costos de producción de naringenina de importancia para la industria farmacéutica y alimentaria.

\section{AGRADECIMIENTOS}

Los autores agradecen al Consejo de Investigación de la Universidad Nacional de Tucumán.

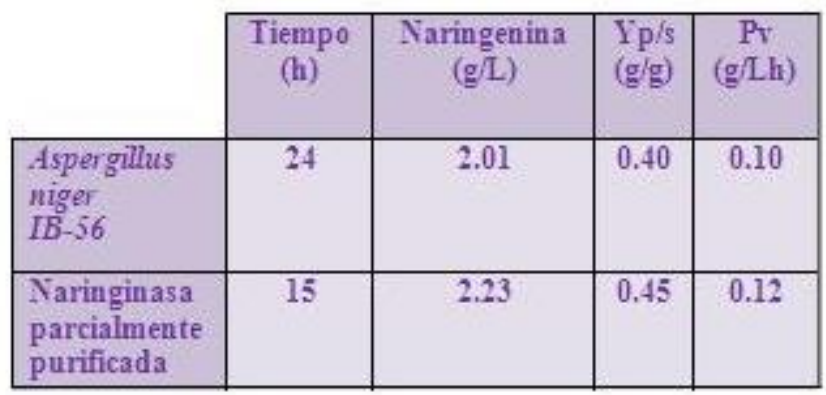

Tabla 1: Parámetros fermentativos de la producción de naringenina obtenidos por Aspergillus niger IB-56 y con naringinasa parcialmente purificada. Concentración de naringenina (g/L); Productividad (Pv) y Coeficiente de Rendimiento de producto (Yp/s). 


\section{REFERENCIAS}

Borradaile, N.; de Dreu, L. \& Huff, M. (2003). Inhibition of net HepG2 cell apolipoprotein B secretion by the citrus flavonoid naringenin involves activation of phosphatidylinositol 3-kinase, independent of insulin receptor substrate-1 phosphorilation. Diabetes. 52: 2554-2561.

Bourbouze, R; Perchero, F. \& Courtois, J. (1976). -Lrhamnosidase from Fagopyrum esculentum. Purification et vuelques propiétés. Eur. J. Biochem. 63:331-337.

David, W. B. (1947) Determination of flavonones in citrus fruits. Anal. Chem. 19: 476.

Doran, M. P. (1998) Introducción a los cálculos de ingeniería. En: Principios de ingeniería de los bioprocesos Edt. Acribia, S.A. Zaragoza. pp. 9-27.

Gallego, M.V.; Piñaga, F.; Ramón, D. \& Vallés, S. (2001). Purification and characterization of an $\alpha$-L-rhamnosidase from Aspergillus terreus of interest in winemaking. J. Food Sci. 66:204209.

González Gallego, J.; Sánchez Campos, S. \& Tuñón, M. (2007). Anti-inflammatory properties of dietary flavonoids. Nutr. Hosp. 22: 287-293.

Habelt, K. \& Pittner, F. (1983) A rapid method for the determination of naringin, prunin and naringenin applied to the assay of naringinase. Anal. Biochem. 134:393-397.

Hui, N.; Lijun, L.; Anfeng, X.; Ying, C.; Yuelong, CH. \& Huinong, C. (2011) Identification and characterization of a new naringinasa-producing strain Williopsis californica Jmodeb007. World J. Microbiol. Biotechnol. Online first

Johnson, R. \& Chandler, B. (1988) Adsorptive removal of bitter principles and titrable acid from citrus juice. Food. Technol. 45: 130-137.

Kurosawa, Y.; Ikeda, K. \& Egami, F. (1973). $\alpha$-L-rhamnosidase of the liver of Turbo cornutus and Aspergillus niger. J. Biochem. $73: 31-37$.

Martín, J. \& Demain A. (1978) Fungal Development and metabolite formation In: The filamentous fungi. (ed) Smith J \& Berry, D. (Edt.) Arnold Edward. London. Vol. 3. pp. 426-448.
Nahmias, Y.; Goldwasser, J.; Casali, M.; Van Poll, D.; Wakita, T.; Chung, R. \& Yarmush, M. (2008) Apolipoprotein B-dependent hepatitis $\mathrm{C}$ virus secretion is inhibited by the grapefruit flavonoid naringenin. Hepatology 47: 1437-1445.

Puri, M. \& Banerjee, U. (2000) Production, purification and characterization of the debittering enzyme naringinase. Biotechnol. Adv. 18: 207-217.

Puri, M. \& Karla, S. (2005) Purification and characterization of naringinase from a newly isolated strain of Aspergillus niger 1344 for the transformation of flavonoids. World J. Microbiol. Biotechnol. 21: $753-758$.

Puri, M.; Kaur, H.; \& Kennedy, J. F. (2005) Covalent immobilization of naringinase for the transformation of a flavonoid. J. Chem. Technol. Biotechnol. 8: 1160-1165.

Puri, M.; Marwaha, S. \& Kothari, R. (1996) Studies on the applicability of alginate-entrapped naringinase for the debittering of kinnow juice. Enzyme Microbiol. Technol. 18:281-285.

a ekeroçlu, G.; Fadiloçlu, S. \& Göçûs, F. (2006). Immobilization and characterization of naringinase for the hydrolysis of naringin. Eur. Food Res. Technol. 24: 55-60.

Somogyi, M. (1945) A new reagent for the determination of sugars. J. Biol. Chem. 160-168.

Soria, F. \& Ellenrieder, G. (2002) Thermal inactivation and product inhibition of Aspergillus terreus CECT $2663 \alpha$-Lrhamnosidase and their role on hydrolysis of naringin solutions. Biosc. Biotechnol. Biochem. 66:1442-1449.

Vila Real, H.; Alfaia, A.; Calado, A. \& Ribeiro, M. (2006) High pressure-temperature effects on enzymatic activity: Naringin bioconversion. Food Chem. 102:565-579.

Wainwright, M. (1992). Técnicas de producción en biotecnología de hongos. En: Introducción a la biotecnología de los hongos. Edt. Acribia. España. pp. 31-39.

Yusof, S.; Gazali, H. \& King, G. (1990) Naringin content in local citrus fruit. Food chem. 37: 113-121. 